\title{
Exploring the Common Spaces of Education and Complexity: Transphenomenality, Transdisciplinarity, and Interdiscursivity
}

BRENT DAVIS, Co-Editor

University of Alberta (Canada)

RENATA PHELPS, Co-Editor

Southern Cross University (Australia)

At the most recent Complexity Science and Educational Research Conference (held in Loranger, Louisiana in November, 2005), one of the dinner conversations revolved around the ways that the word "they" is used in discussions of education. The term might be in reference to individual students, or to clusters of neurons, or to classrooms, or to the world of adolescents, or to society, or any of a number of coherent collectives that are of relevance to the educational project.

The actual prompt for the conversation was one participant's realization that, in the same sentence, another person at the table had used "they" four times in reference to four distinct phenomena-namely, individual learners, educators, neurologists (or, more precisely perhaps, the field of neurology), and funding agencies. More surprisingly, despite the obvious potential for confusion, the threads of the conversation did not become tangled. The four-they sentence was completely coherent to everyone present, signaling to us that we educators were adept level-jumpers, able to move fluidly among and across different levels of complex activity.

Or, phrased in a slightly different way, we were comfortable living with the transphenomenal character of educational phenomena. Indeed, as the 
conversation moved into a more critical examination of the labile meanings of the word "they," it was noted that something as "simple" as a personal understanding of a physical event was likely rooted in biological structure (genetic predisposition), framed by bodily activity (personal experience), elaborated within social interactions (symbolic tools), enabled by cultural tools (societal usages), and part of an ever-unfolding conversation of humans and the biosphere. Unfortunately, in the main, the education literature simply does not treat such topics in this manner. Rather, investigations of issues such as personal understanding and interpretation sometimes seem to be oriented by an assumption that one level of analysis (e.g., the neurological level, or the symbolic-linguistic level) is sufficient for making sense of the matter.

Complexity thinking troubles this habit in its recognition that the sorts of phenomena listed in the previous paragraph evolve at radically different paces, prompting impressions that some "things" are inherently volatile (e.g., personal sense-making) while others are essentially fixed (e.g., genetic structure). And so, while it prompts attentions to the transphenomenal character of education, complexity thinking simultaneously foregrounds the need for diverse categories of expertise and diverse methodologies when studying any aspect of the educational endeavor. In other words, a phenomenon as "simple" as personal understanding demands a transdisciplinary attitude.

Just as transphenomenality entails a sort of level-jumping, transdisciplinarity compels a sort of border-crossing - a need to step outside the limiting frames and methods of phenomenon-specific disciplines. Most obviously, perhaps, this realization serves as a powerful refutation of the early 19th-century assertion that education is an "applied psychology" , or the more recent contention that teaching should be construed as an "applied science of the brain" (Zull, 2002). Clearly, such formulations engender profound ignorances of the complexity of the phenomenon at hand. Of course, this is not a new insight to education or to educational research, where it is not unusual to encounter references to neurology, psychology, sociology, anthropology and other domains in the same research paper. What has proven more troubling, however, is the seeming irreconcilability of some of the more prominent discourses within these domains. The discourses that support and are supported by the various disciplines are commonly seen as incompatible, if not flatly contradictory.

Complexity thinking provides a means around this apparent impasse, and it does so by emphasizing the need to study phenomena at the levels of their emergence, oriented by the realizations that new stable patterns of activity arise and that those patterns embody emergent rules and laws that are native to the system. This piece of advice requires that researchers pay 
particular attention to the paces of evolution at hand. For example, biological structure transforms over millennia and eons, and is thus sufficiently stable to lend itself to the assumptions of analytic science. By contrast, other phenomena, such as a culture's symbolic tools, not only evolve more quickly, but are subject to very different sets of influences. Analytic methods are simply inappropriate to make sense of such disperse, rapidly changing, intricately entangled sets of phenomena.

It is thus that complexity thinking might be described as a sort of interdiscourse. Invoking a post-structuralist usage, a discourse is a structurally coherent domain of language use, along with the activities associated with the use of that language, that organizes and constrains what can be said, done, and thought. Every discourse has its own distinctive set of rules, usually operating implicitly, that govern the production of what is to count as meaningful and/or true. Discourses always function in relation to, or in opposition to, other discourses. No discourse stands alone, although some (such as fundamentalist religion, scientism, or modernism) lay claim to a certain totalized and exclusive understanding of the universe.

Post-structuralist theory has contributed to understandings of interdiscursivity - that is, how discourses intersect, overlap, and interlace. But post-structuralism has been less effective at providing insight into how discourses intersect, overlap, and intersect with phenomena. Complexity thinking helps here by pressing beyond the boundaries of intersubjective constructions, as it refuses to collapse phenomena with knowledge of phenomena. These are inextricably entangled, but not coterminous.

As such, complexity thinking enables a simultaneous appreciation of the insights of such disparate discourses as post-structuralism and analytic science. Notably, as a collective, educational researchers have acknowledged this point. Considered collectively, the educational research literature is informed by analytic philosophy, phenomenology, structuralism, post-structuralism, psychoanalysis, ... the list goes on. What is not so well represented-within single publications, at least-is the necessity of interdiscursivity. Indeed, most often in the contemporary literature, discourses are presented as oppositional rather than complementary. This sort of conclusion is inevitable if the transphenomenal character of educational 'objects' is not taken into consideration.

In this issue of Complicity, we are pleased to feature articles that take on issues of transphenomenality, transdisciplinarity, and interdiscursivity. In our first article, for example, Elizabeth Burris looks at the organizational level of the classroom to develop the transphenomenal suggestion that these collectivities, like individuals, "can use therapy too." In her discussion, Burris identifies epistemological errors—we might call them interdiscursive slips- 
that can prompt repetitive and pathological actions on the level of the classroom action.

Inna Semetsky develops a similar theme in a very different way in her article "Not by breadth along: Imagining a self-organized classroom." Semetsky focuses on the problematic of language and communication to interpret the educational significance of Deleuzian thought. Echoing the notions of level-jumping and border-crossing, Semetsky notes that the "macro-perspective of a single theory, or meta-narrative, is insufficient," calling forth the need for a simultaneous recognition of "the micro-political and micro-perception dimension as a contextual site."

Renata Phelps addresses another manifestation of transphenomenality in her article, "The potential of reflective journals in studying complexity 'in action'." Reporting on the use of reflective journals within action research projects, Phelps navigates the interplay of individual and collective transformation, attending in particular to the necessary sources of disequilibrium that are needed to keep these nested phenomena vibrant and adaptive.

Donald Gilstrap looks across even broader levels of organization as he explores the utility of strange attractor metaphors for helping us to understand issues in educational leadership and teaching, including shared vision, team processes and information flows. In his discussion, he demonstrates the importance of transphenomenal level-hopping and transdisciplinary border-crossing as he comments on phenomena ranging from the governmental to the individual and draws on an extensive literature that includes references to the natural sciences, linguistics, sociology, and several other domains.

Gilstrap's provocative usage of metaphor serves as an apt segue to a new feature of Complicity. As we develop in the introduction to the section entitled "Semantic Play and Possibility," we wondered how complexity science might prompt rethinkings of prominent terms in educational discourse. "Semantic Play" is followed by a collection of book reviews assembled and introduced by our Book Review Editor, Kristopher Wells.

\section{Reference}

Zull, J.E. 2002. The art of changing the brain: Enriching the practice of teaching by exploring the biology of learning. Sterling, VA: Stylus.

(C) Copyright 2005. The authors, Brent Davis and Renata Phelps, assigns to the University of Alberta and other educational and non-profit institutions a non-exclusive license to use this document for personal use and in courses of instruction provided that the article is used in full and this copyright statement is reproduced. The authors also grant a non-exclusive license to the University of Alberta to publish this document in full on the World Wide Web, and for the document to be published on mirrors on the World Wide Web. Any other usage is prohibited without the express permission of the authors. 